experimentally proved and, indeed, it seems highly improbable that seminal fluid can reach the fundus uteri or the tubes where fertilization takes place. Here again the question of a stage of spirochetal development in which the organism is sufficiently small to be borne into the ovum on the spermatozoön, is the most probable reason for paternal infection. Granting thus that the ovum may be infected by the father, does the mother necessarily become infected, or may the placenta act as a barrier? Reasoning a priori, the latter is most probably the case, inasmuch as placental transmission has not been proved. Edgar admits that "we know little of germinal and embryonal syphilis."

It may be said in conclusion that the entire subject of hereditary and congenital syphilis requires an immense amount of research in order to establish the true laws underlying it, and that with the resources at our command, hospitals having obstetric services should institute an investigation of the problem, utilizing the obstetrician, the pathologist, the serologist, the pediatrician and often the correlated members of the staff in the search for its solution.

348 SOUTH FIFEENTH STRETS.

(For discussion see page 6.55.)

\title{
PELVIORADIOGRAPHY AFTER FABRE'S METHOD
}

By J. Warken Bell, M.D., Minneapolis, Minj.

TWO years ago I was attracted by the description of a method of pelvimetry by Fabre, based upon an intelligent use of the x-ray.

Upon reviewing American literature with reference to this work, I found it in print but once, and then only given passing mention in Dr. William's Text Book of Obstetries. I resolved to try the process, and I have convinced myself that, with practice, this method can be made to give excellent results. Through the courtesy of Dr. J. C. Litzenberg six plaster models of deformed pelves were studied at the University Hospital of Minnesota by the operator, Miss Bagameil. The results of this study showed that the greater the deformity of the pelvis the more difficult it became to place the frame in the proper position for obtaining aecurate results. Where the deformities were not extreme, some of the results very closely coincided with the true measurements of the models.

Next a skeleton was placed in the frame (Fig. 2), and from the print the outline of the inlet was drawn upon graph paper and then cut out of cardboard. This piece of cardboard fitted within $0.5 \mathrm{~cm}$. the size of the inlet.

I quote from the text of the originator of the method the following, with due apologies for the translation. 
Precis d'Obstétrique par Fabre, p. 512.

As a result of the difficulties of application of pelvimetry by Focher, I decided to apply radiograpliy to the study of contracted pelves.

Pelviography presents some very important advantages: the process is painless: it is of easy application during pregnancy, and gives very exact results: by an antomatic process, the accoucheur may have precise therapentic indications, and after confinement, it verifies the fact, if the operations employed were indicated.

The disadvantages of radiography are due to the nature of the $x$-rays, which leaving the cathode, diverge and distort the image. If one tries to reproduce the outlines of the superior strait, the image is not only enlarged, but furthermore the distortion is irregular, for it is impossible to place the patient in such a position that the plane of the superiog strait is exactly parallel to the photographic plate. The consequence is that the bony portions most distant from the sensative plate are enlarged and deformed: the portions near the plate are less distorted.

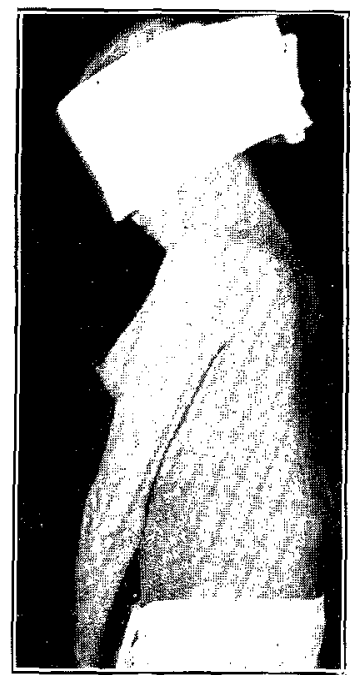

Fig. 1.-Lateral view of patient, showing spinal deformity.

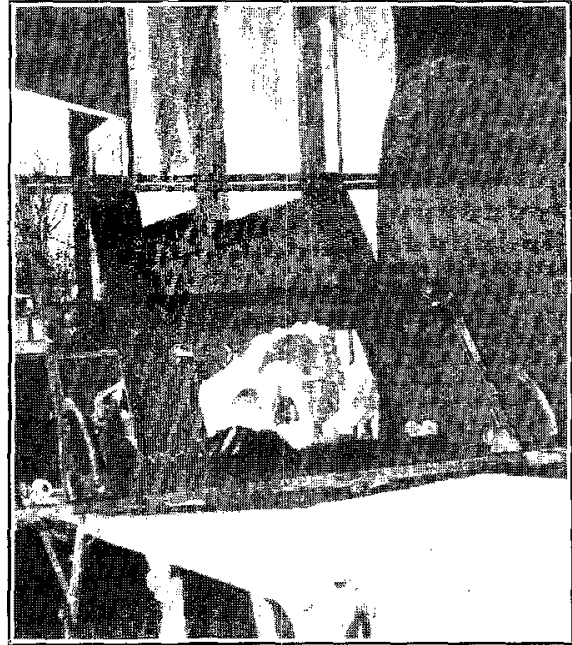

Fig. 2.-Frame, with skeleton in the position of patient. Legs are removed.

Indications of Betric Radiography.-

1. Before marriage. In all cases where the skeleton presents a congenital or acquired deformity, congenital dislocation of the hip, either unilateral or bilateral, infantile paralysis and hemiplegia; white tumors of the lower limbs, coxalgia, early or late rickets, etc.

2. During pregnancy. At a time anywhere in pregnancy there is an indication for radiography of the patient whenever one has the presumptive signs of lesions of the pelvis, and more emphatically when one has absolute signs. The therapeutic decisions should be based upon exact measurements of the inlet.

3. After confimement. Every time that the mechanism has presented anything particular, or that the abnormality cannot be explained by elinical examiuation. The conduct of the next confinement would then be established with certainty.

Process of Metric Radiography.-This consists of radiographing the inlet at the same time that the region is being measured by metallic scales (rules) with lines one centimeter apart. The scales are placed in the plane of the diameter of the pelvis which one wishes to measure. These seales undergo the same distortion as the inlet: 
upon the plate after development, the number of teeth correspond to the number of centimeters, whatever the dimensions of the image.

Metric radiography only gives accurate results for the measuring of the inlet. To obtain this result it is necessary for the plane of the frame to coincide as nearly as possible with the plane of the inlet. But the different diameters of the inlet are not in the same plane. It is for this reason that my frame is double and is composed of four toothed scales which gives two, the anterior and the posterior (which) are in the transverse pubic plane that contains the oblique and transverse diameters, and which gives two lateral scales in the promontopubic plane. Upon the radiogram the four scales make possible the establishment of a quadrangle deformed by the x-rays, but which in extent, corresponds to squares one centimeter on each side. The coineidence of the frame and the planes of the inlet does not have to be absolute to give exact results.

Diffuraties of Application of the Methol.-

1. The nature of the rays employed is not very important. All the radiographie machines have given good radiograms of the pelvis. I, myself use a coil of 50 cms. spark, the automatic interrupter of Gaiffe, a Mueller tube. In the coil I pass

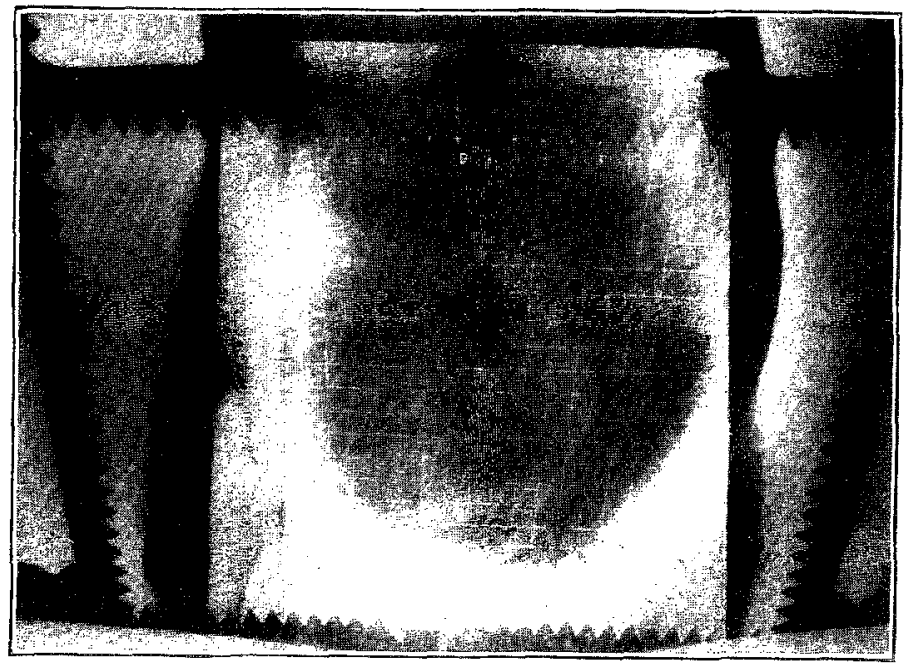

Fig. 3.-Radiogram of pelvis showing notches in frame, and lines joining sane.

three or four amperes at 110 Volts; in the tube five milliamperes; the time of exposure is from three to five minutes, the spark compensation being ten centimeters. With the new installation of intensive radiography the picture of the pelvis is obtained in ten to twenty seconds. It is essential not to have the rays too penetrating, lest they traverse the promontory without giving the image. The process is applicable at any period of pregnancy.

2. Distance of the tube from plate. I have adopted a distance of 50 cms. as a fixed distance. At this distance the harmful influences upon the fetus or the skin of the mother are nil. I lave never encountered an aceident.

3. Necessity of the ventral position.-In this posilion alone it is possible to obtain a good inage of the inlet; only then is the promontory well defined. The importance of this particular point is considerable and explains our good results. On the contrary, in the corsal position, the image reproduces the posterior surface of the sacrum, the promontory is invisible and the circumference of the inmominate line is not reproduced. 
Manual Operation.-.

1. Determination of the point of the pubie landmark. The patient is placed in the dorsal position. One determines the upper border of the pubis and one $\mathrm{cm}$. below this border one traces with a ruler and a dermographic pencil, a horizontal line which extends over the sides of the thighs: this line permits us to be assured, when the patient is lying on her abdomen, that the anterior seale of the frame is in the proper relation to the upper borders of the pubis.

2. Determination of the posterior landmark. The patient lies on her abdomen. One traces a horizontal line which passes across the dimples of the rhomboid of Michaelis: this line corresponds to a line parallel with the transverse pubic plane of the inlet. Above this, one draws a second line, 3, 4, or $6 \mathrm{cms}$. according to whether the promontory has been established low, normal, or high by vaginal examination. In cases where the vaginal examination should not be done (as before marriage), the point for the upper landmark is fixed at 4 cms. above the line through the dimples.

3. The patient is placed in the frame. The patient is placed in the frame, lying upon her stomach, the elbows in front on the cushion. The pubie scalo is made

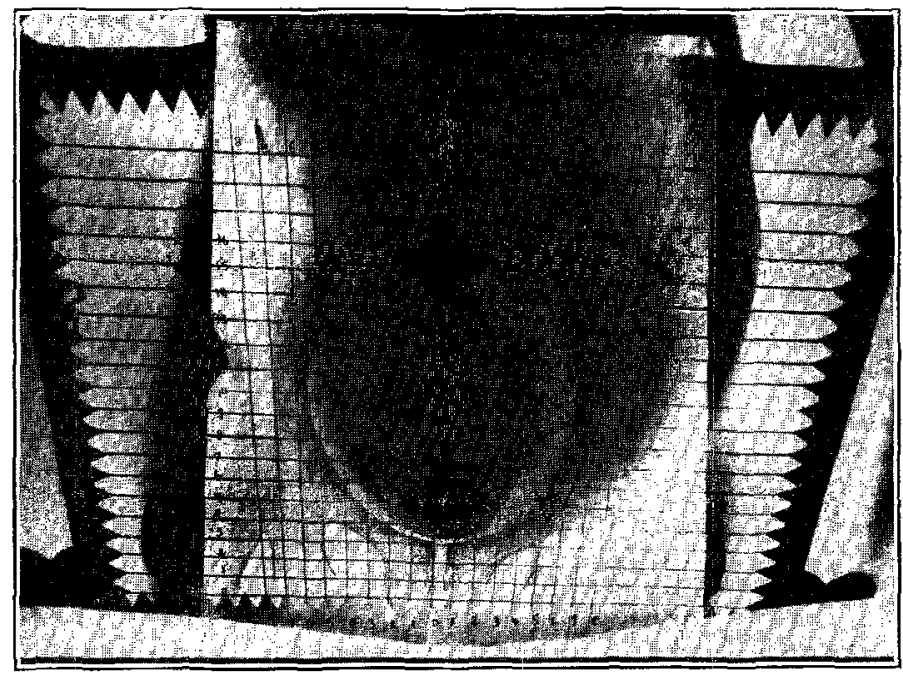

Fig. 4.- Same radiogram retouched.

to coincide with the line which is visible on the lateral aspect of the thighs. The dorsul scale of the transverse pubic plane is in contact with the line of the dimples: the scale of the promontopubic plane (scale enclosed in wood) is in contact with the upper line corresponding to this plane.

4. Manner of placing the tube. The tube is placed upon a vertieal median line, $50 \mathrm{cms}$. above the plate, and the normal rays of incidence fall at the side of the feet 20 cms. from the pubic scale.

5. Duration of exposure. The exposure with our installation lasts from three to six minutes, depending on the corpulency of the patient. During pregnancy the time of exposure is about six minutes. With the installation of the intensive radiography the exposure is less than a minute; with the intensifying screen this is reduced to ten seconds.

6. Development of the negative. The negative is developed exactly like an ordinary photographic plate.

7. Ruling the negative. The opposite teeth of the scales are numbered with pencil, and the corresponding teeth on the pubic scales are joined by straight 
lines traced with pencil upon the negative. The teeth of the lateral promontopubic scales are joined by straight lines. One thus obtains an irregular quadrangle with sides of one $\mathrm{cm}$.

8. Location upon squares. To reduco the radiogram and give the inlet its true dimensions, it suffices to reproduce the curves of the inlet upon one $\mathrm{cm}$. square "graph" paper, by marking the points where the curve cuts the limes traced upon the negative.

I have been able to empare, in a certain number of cases, the radiogram made during life, with the pelris, recovered at autopsy. The errors were about $2 \mathrm{~mm}$, that is to say, the process is extremely accurate and much more preeise than with all the other clinical processes of measuration.

During the last ten years the process has rendered me great service from the clinical point of view, and I have been able to establish a true radiograply of the pelvis actually in 638 radiograms.

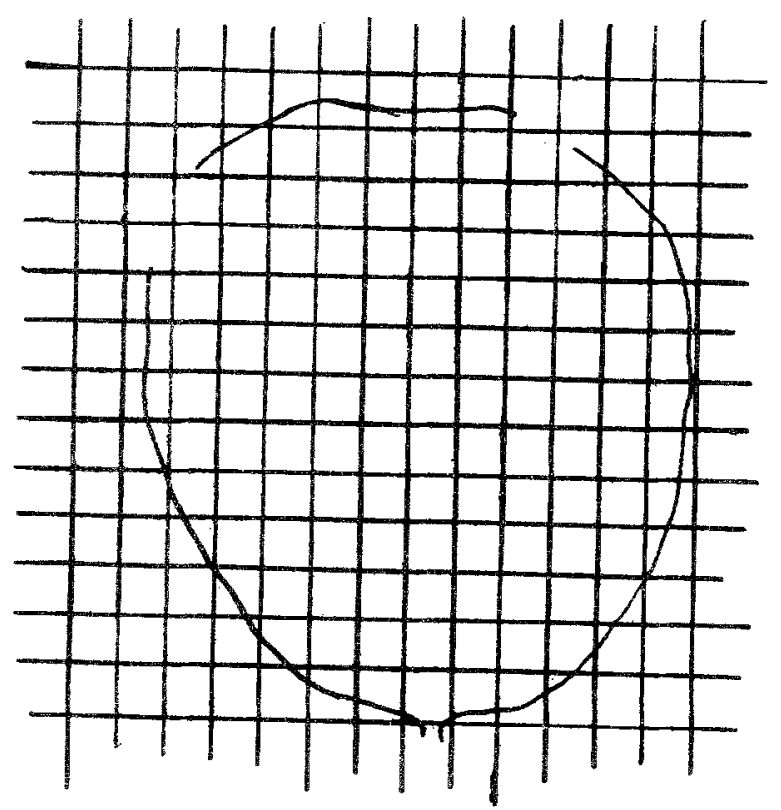

Fig. 5.-Showing uttine of velvic inlet plotted on graph paper with centineter squares.

The above paragraphs show what this method has done in France. I present herewith a ease history, with notes pertaining to the application of this method.

In Decombor, E. F. appeared at the Free Dispensary. She was about ficet 6 inches tall, had a marked lumbar kyphosis and a slight scoliosis. There was a bump over the lumbosacral region which made the external conjugate measurement valueless. (Fig. 1.) The patient had been ill as a child with spinal caries.

There was a 71/2 months' pregnancy, with exphalic presentation, occiput Iying partly in the inlet. The outlet was measured by several men, and the bituberous measurement was $7.5 \mathrm{cms}$.

By raginal examination the head was found partly in the pelvis and in this position it interfered with taking the internal oblique diameter. The measurements of the pelvis externally were as follows: Interspinous, $233 / 4 \mathrm{~cm}$; intereristal, $2 ;$ em.; intertrochanterie, 26 (m); external conjugate, $20 \mathrm{~cm}$.

The acconnanying radiograms were made. 
Technic.-The patient was placed in the ventral position, with a large casette beneath her abdomen which contains the 17 by 22 inch film and an intensifying sereen 10 by 14 inches.

The tube was placed at a point towards the patient's feet $50 \mathrm{cms}$. from the symphysis, and $50 \mathrm{cms}$. from the table. The tube is so tilted that the direct rays enter the outlet of the pelvis and leave through the inlet.

The frame seen in the illustration, is made of wood, and is adjustable to the size of the patient. The frame is applied as nearly as possible to the plane of the inlet.

This plane is determined by the three points:-the top of the symphysis, and the two dimples of the posterior inferior spines of the ilium.

The wooden frame contains a lead layer with notched edges, the notches being one $\mathrm{cm}$. apart.

The film must be large enough to show the shadow of the entire frame.

Reading the Film.-By joining opposite notches the accurate measurements of the picture of the pelvis can be quickly obtained.

In the illustration these connesting lines have heen drawn in (Figs. 3 and 4 ).

From this film, with the unavoidable distortion, a true outline of the inlet has been made upon graph paper with centimeter squares (Fig. 5).

The accompanying sketch shows this outline after the distortion has been removed.

The patient was delivered at the University Hospital, on Dr. Litzenberg's service, and when discharged it was found that the internal diagonal conjugate was larger than $12 \mathrm{~cm}$. I was able to verify this later, and feel justified in reporting the case as a successful application of Fabre's mechod of radiopelvimetry.

600 Phrsidians and Surgeons Bulloing.

\section{FIBROMYOMA OF THE UTERUS ACCOMPANIED BY HYPERTHYROIDISM}

By William M. Thompson, M.D., F.A.C.S., Chicago, Ill.

$\mathrm{T}$ HAT a relationship exists between the sexual system and the thyroid gland has long been known. The ancients recognized the thyroid as the sex gland in man and animals. Paleontologists have demonstrated the existence of the thyroid as derived from the uterus of paleostrean ancestors. Hypo- and hyperthyroidia as a factor in sexual changes has been known for several centuries, but it was not until 1859 and 1862 that Chareot's publication brought the knowledge of his day into tangible form. Until recent years our knowledge was chiefly clinical, probably beginning with Halstead ${ }^{1}$ in 1888 and 1889, but modern observers have been adding experimental to clinical data, until today the thyroid is recognized as the chief regulator of metabolism. The iodine or iodine-containing hormone of the thyroid is the most powerful activator of metaholism as a stimulus of the oxidation process. This stimulus causes a work hypertrophy of the gland, which is evidenced in menstruation and pregnaney. 